\title{
O benefício da justiça gratuita e a necessidade ou não de comprovar a insuficiência
}

\section{de recursos}

The benefit of free justice and the need or not to prove insufficient resources

EI beneficio de la justicia gratuita y la necesidad o no de demostrar recursos insuficientes

Celso Hiroshi Iocohama

ORCID: https://orcid.org/0000-0002-0686-0330 Universidade Paranaense, Brasil

E-mail: celso@prof.unipar.br

Cleverson Daniel Dutra

ORCID: https://orcid.org/0000-0002-3810-6391 Universidade Estadual do Mato Grosso do Sul, Brasil

E-mail: cleverson@uems.br

Kimberly dos Santos Manduca

ORCID: https://orcid.org/0000-0001-9927-5570

Universidade Paranaense, Brasil

E-mail: kimberly.manduca@edu.unipar.br

\begin{abstract}
Resumo
A garantia de acesso à justiça é um direito fundamental, previsto na Constituição Federal, onde se estabeleceu o princípio da inafastabilidade da jurisdição, garantindo o livre acesso ao Judiciário, tendo este dado respaldo a gratuidade da justiça. A Lei 13.105/15 ao prever a Justiça Gratuita consagrou temas consolidados pela jurisprudência e doutrina, porém, não estabeleceu os critérios para a concessão. Dessa forma, o problema a ser analisado neste artigo é sobre a necessidade ou não de comprovar a insuficiência de recursos e a ausência de parâmetros no ordenamento jurídico. A metodologia adotada é da pesquisa bibliográfica, com abordagem descritiva e dedutiva sobre o tema. Para requerer o benefício basta uma declaração afirmando ser hipossuficiente, demonstrando assim uma facilidade. Em razão disso alguns doutrinadores defendem que somente terá o deferimento a declaração da hipossuficiência vier acompanhada de documentos que comprovem sua real situação financeira, pois a declaração tem presunção relativa. Porém, a juntada desses documentos não é uniforme, cada magistrado tem pedido a juntada dos documentos de acordo com o que acredita ser suficiente e de acordo com o caso concreto. Há, contudo, uma minoria na jurisprudência que tem julgado como suficiente apenas a declaração da hipossuficiência. Nota-se que cada juiz utilizará seus próprios critérios subjetivos e discricionários, não possuindo uniformização quanto à concessão do benefício de justiça gratuita, fazendo com que a lei seja aplicada de modo desigual e propiciando a sensação de insegurança jurídica.

Palavras-chave: Justiça gratuita; Insuficiência de recursos; Necessidade de comprovação; Ausência de critérios legais; Desigualdade.
\end{abstract}

\begin{abstract}
The guarantee of access to justice is a fundamental right, provided for in the Federal Constitution, which established the principle of non-removal of jurisdiction, guaranteeing free access to the Judiciary, which supports the gratuitousness of justice. Law 13,105/15, when providing for Free Justice, established themes consolidated by jurisprudence and doctrine, however, it did not establish the criteria for granting it. Thus, the problem to be analyzed in this article is about the need or not to prove the insufficiency of resources and the absence of parameters in the legal system. The methodology adopted is bibliographic research, with a descriptive and deductive approach on the subject. To apply for the benefit, a declaration stating that it is low-sufficient is enough, thus demonstrating an ease. For this reason, some scholars defend that only the declaration of hyposufficiency will be granted with documents that prove their real financial situation, as the declaration has relative presumption. However, the attachment of these documents is not uniform, each magistrate has requested the attachment of documents according to what he believes to be sufficient and according to the specific case. There is, however, a minority in the jurisprudence that has judged as sufficient only the declaration of hypo-sufficiency. Note that each judge will use their own subjective and discretionary criteria, not having uniformity regarding the granting of the benefit of free justice, causing the law to be applied unequally and providing the feeling of legal uncertainty.
\end{abstract}

Keywords: Free justice; Insufficiency of resources; Need for proof; Absence of legal criteria; Inequality. 


\begin{abstract}
Resumen
La garantía de acceso a la justicia es un derecho fundamental, previsto en la Constitución Federal, que estableció el principio de no remoción de competencia, garantizando el libre acceso al Poder Judicial, que sustenta la gratuidad de la justicia. La Ley 13.105 / 15, al disponer la Justicia Libre, estableció temas consolidados por la jurisprudencia y la doctrina, sin embargo, no estableció los criterios para su otorgamiento. Así, el problema a analizar en este artículo es sobre la necesidad o no de probar la insuficiencia de recursos y la ausencia de parámetros en el ordenamiento jurídico. La metodología adoptada es la investigación bibliográfica, con un enfoque descriptivo y deductivo del tema. Para solicitar el beneficio, basta con una declaración que indique que es bajo suficiente, demostrando así una facilidad. Por ello, algunos estudiosos defienden que solo se otorgará la declaración de hiposuficiencia con documentos que acrediten su situación económica real, ya que la declaración tiene presunción relativa. Sin embargo, el adjunto de estos documentos no es uniforme, cada magistrado ha solicitado el adjunto de documentos según lo que crea suficiente y según el caso concreto. Sin embargo, hay una minoría en la jurisprudencia que ha juzgado como suficiente únicamente la declaración de hipoactividad. Nótese que cada juez utilizará sus propios criterios subjetivos y discrecionales, no habiendo uniformidad en cuanto al otorgamiento del beneficio de la justicia gratuita, provocando que la ley se aplique de manera desigual y dando la sensación de inseguridad jurídica.
\end{abstract}

Palabras clave: Justicia libre; Insuficiencia de recursos; Necesidad de prueba; Ausencia de criterios legales; Desigualdad.

\title{
1. Introdução
}

O acesso à justiça é tema de grande importância no ordenamento jurídico, sendo considerado um direito fundamental, conforme prescrição do art. 5, inciso XXXV, da Constituição da República Federativa do Brasil de 1988.

Nesse dispositivo constitucional encontra-se o princípio da inafastabilidade da jurisdição, segundo o qual a lei não excluirá da apreciação do Poder Judiciário lesão ou ameaça a direito, garantindo o livre acesso ao Judiciário.

O pedido de gratuidade da justiça tem respaldo no princípio constitucional da inafastabilidade do controle jurisdicional e o direito está referido no art. 5 , LXXIV, da Constituição da República Federativa do Brasil de 1988, segundo o qual “o Estado prestará assistência jurídica integral e gratuita aos que comprovarem insuficiência de recursos” (Brasl, 1988). Portanto, essa garantia constitucional assegura aos hipossuficientes a prestação de assistência judiciária gratuita.

De acordo com Lima (2013, p. 118) o preceito elencado no art. 5º, inciso XXXV, da Constituição da República Federativa do Brasil de 1988, “estabelece para o direito de ação, caracterizando o ponto fulcral de um verdadeiro regime jurídico concernente a este instituto fundamental do Direito Processual". Caminhando neste sentido, a Lei 13.105 , de 16 de março de 2015 prevê, em seus Artigos 98 a 102, o novo regramento da Justiça Gratuita, como forma de consagrar temas consolidados pela jurisprudência e doutrina (modulado pela Lei 1.060/1950) e inovar disposições normativas.

Apesar da Lei 13.105/2015, que instituiu o Novo Código de Processo Civil, regulamentar o assunto de forma detalhada, especialmente sobre a simplificação do procedimento na concessão do benefício de gratuidade da justiça na órbita procedimental civil, existem circunstâncias que ainda são alvo de debates, relegando o deferimento ao critério do julgador e quiçá dos tribunais.

Dessa forma, o presente artigo tem como finalidade, de forma concisa, analisar a problemática da necessidade ou não de comprovar a insuficiência de recursos e a ausência de parâmetros no ordenamento jurídico no que diz respeito à concessão do benefício da justiça gratuita, elencando o que mudou na sistemática na concessão do benefício da justiça gratuita, trazendo algumas impressões preliminares obtidas na análise da Constituição Federal, dos artigos 98 a 102 da Lei 13.105/2015 e o posicionamento da jurisprudência.

\section{Metodologia}

A pesquisa científica jurídica é rica e farta de produções acadêmicas onde se desenvolve um processo de investigação com o objetivo de solucionar, responder ou aprofundar problemas que surgem em meio a sociedade ou simplesmente na 
academia. Para Bastos e Keller (1995, p.53) "A pesquisa é requerida quando não se dispõe de informações suficiente para responder ao problema, ou então quando a informação disponível se encontra em tal estado de desordem que não pode ser adequadamente relacionada ao problema".

A pesquisa científica apresenta várias modalidades, sendo uma delas a pesquisa bibliográfica que foi utilizada neste artigo. Ela está inserida principalmente no meio acadêmico e tem a finalidade de aprimoramento e atualização do conhecimento, através de uma investigação em obras já publicadas. Nela o pesquisador busca obras já publicadas relevantes para conhecer e analisar o tema problema da pesquisa a ser realizada. A pesquisa bibliográfica auxilia desde o princípio, pois é feita com intuito de identificar se já existe alguma produção de natureza cientifica sobre o assunto, colaborando na escolha do problema e de um método adequado, tudo isso, tomando por base os trabalhos já publicados.

Ao aplicar a pesquisa bibliográfica para verificar as possíveis abordagens a serem apresentadas e com o intuito de apurar a base referencial para a produção textual, a abordagem usada foi a descritiva, onde no desenvolvimento o tema foi esboçado por meio da apresentação dos conceitos básicos e essenciais a serem aplicados ao problema e verificando possíveis conflitos deste conceito ou ideias com outros temas. Depois buscou-se apresentar o contexto histórico a qual o instituto da Justiça Gratuita surgiu e seu desenvolvimento legislativo e doutrinário. Ao discorrer sobre o tema, o método dedutivo foi aplicado com o objetivo de levar o pesquisador a concluir como o tema evoluiu ao longo do tempo e como se dá a sua aplicação no sistema processual civil, à luz da nova legislação.

\section{Resultados e Discussão}

\subsection{Justiça gratuita}

\subsubsection{Definição do acesso à justiça}

Primeiramente, é necessário saber o conceito da palavra justiça na forma lato senso, pelo fato de a sociedade estar sempre utilizando essa palavra em diversas circunstâncias.

Ao buscar o significado da palavra justiça no dicionário Aurélio, encontra-se a seguinte definição: “a virtude de dar a cada um aquilo que é seu; faculdade de julgar segundo o direito e melhor consciência; magistratura; conjunto de magistrados judiciais e pessoas que servem junto deles; o pessoal dum tribunal; o Poder Judiciário" (Ferreira, 2010, p. 450).

O significado da palavra justiça à luz dos pensamentos filosóficos possui diversas definições. Na visão Aristotélica a justiça é o ato de cada ser humano dar ao outro o que é seu, de acordo com seus méritos, não pegar nada que não seja seu e nem menos do que lhe é devido. Dessa forma, segue sua opinião:

A justiça é a forma perfeita de excelência moral porque ela é a prática efetiva da excelência moral perfeita. Ela é perfeita porque as pessoas que possuem o sentimento de justiça podem praticá-la não somente a sim mesmas como também em relação ao próximo (Aristóteles, 1996, p. 195).

Rawls (2000, p. 13) conceitua justiça da seguinte forma:

Como cada pessoa deve decidir com o uso da razão ou que constitui o seu bem, isto é, o sistema de finalidade que, de acordo com a sua razão, ela deve buscar, assim um grupo de pessoas deve decidir uma vez por todas tudo aquilo que entre elas se deve considerar justo ou injusto.

Existem diversos conceitos sobre a palavra justiça, bem como sobre o que é justo. Além disso, sabe-se que a justiça não está somente ligada à lei, justiça é muito mais que isso e deve ser analisada de acordo com o contexto social.

Com isso, considera-se que conceituar o acesso à justiça é uma missão difícil, pois não é um conceito universal, está sempre em transformação e sua definição pode variar de acordo com o tempo e espaço. 
Uma definição comum do acesso à justiça é ancorada na Constituição da República Federativa do Brasil de 1988 em seu artigo $5^{\circ}, \mathrm{XXXV}$, que apresenta uma definição de acesso à justiça como um simples acesso ao Poder Judiciário e também como sinônimo do princípio da inafastabilidade do controle jurisdicional.

Com os movimentos e reformas constitucionais e processuais da década de 1980, o conceito de acesso à justiça passou por transformações e segundo Cappelletti e Garth $(1988$, p. 12) afirmam que "atualmente o acesso à justiça tem sido considerado como um requisito essencial e o mais básico dos direitos humanos".

Com isso, o conceito de acesso à justiça, deixa de ser simplesmente um acesso ao Judiciário e passa ter sentido de acesso a direitos, as pessoas poderão ter acesso à juridicidade independente de uma intervenção judicial, pois poderá ser um acesso ao Judiciário, mas não é aquele simples acesso é ter a garantia de que o seu direito será tutelado e efetivado.

Sendo assim, considera-se que o acesso à justiça tem caráter duplo, podendo ser um meio ou um instrumento que permite um acesso ao sistema Judiciário para que as pessoas possam reivindicar seus direitos e solucionar lides, que seria o sinônimo do acesso ao Judiciário, pois independe que esses direitos sejam protegidos.

Sua outra finalidade está ligada a uma visão ética, valorativa e axiológica da palavra justiça, é o princípio do acesso à justiça sendo desassociado do acesso ao Judiciário e tendo seu sentido por si próprio; indo além de sua primeira finalidade, é o valor de justiça pela sociedade, é um direito individual que vai de encontro ao direito social; é um direito fundamental, humano e essencial para que se exerça a cidadania.

O acesso à justiça sendo analisado sobre o prisma de acesso ao Judiciário, não seria tão eficaz, pois de nada adianta garantir o acesso à justiça, permitindo o acesso ao Judiciário se o direito que se pede não for efetivado e tutelado, pois além de permitir o acesso à justiça é necessário garantir um acesso efetivo, célere, adequado e com qualidade, ou seja, que o sistema jurídico não se esgote em apenas proclamar direitos, mas que os efetive.

Dessa forma, verifica-se que o acesso à justiça pode ser visto de duas formas, ou seja, em dois sentidos. O primeiro sentido é aquele formal, sendo um instrumento para entrar no Poder Judiciário de forma que possa demandar pelos seus direitos e o outro, material, é a efetividade, ou seja, o Poder Judiciário garantindo que aquele que ingressou com a demanda tenha seus direitos efetivados, resultados concretos, de forma que garanta uma verdadeira justiça.

\subsubsection{Diferença dos institutos de assistência judiciária, assistência gratuita e justiça gratuita}

Assistência Judiciária, Assistência Gratuita e Justiça Gratuita, são meios para obter o acesso à justiça, mas não é destinada para toda a sociedade, mas somente para aqueles que não possuem condições de arcar com as despesas de um processo. Muitas vezes, esses institutos são tratados como sinônimos, porém cada um deles possui sua singularidade.

Didier e Oliveira (2016, p. 24) define esses institutos da seguinte forma:

O benefício da justiça gratuita é, como dito, a dispensa do adiantamento de despesas processuais, para o qual se exige a tramitação de um processo judicial, o requerimento da parte interessada e o deferimento do juízo perante o qual o processo tramita. A assistência judiciária consiste no direito de a parte ser assistida gratuitamente por um profissional do Direito, normalmente membro da Defensoria Pública da União, dos Estados ou do Distrito Federal, e que não depende do deferimento do juízo nem da existência de um processo judicial. A assistência jurídica é um conceito mais amplo, que abrange o benefício da justiça gratuita e assistência judiciária, mas vai além deles, englobando todas as iniciativas do Estado (em sentido amplo) que tem por objetivo promover uma aproximação entre a sociedade e os serviços jurídicos.

Já Nery Júnior (1997, p. 94), define Assistência Jurídica Gratuita da seguinte forma:

Diferentemente da assistência judiciária prevista na constituição anterior, a assistência jurídica tem conceito mais abrangente e abarca a consultoria e atividade jurídica extrajudicial em geral. Agora, portanto, o Estado promoverá a assistência aos necessitados no que pertine a aspectos legais, prestando informações sobre comportamentos a serem 
seguidos diante de problemas jurídicos, e, ainda, propondo ações e defendendo o necessitado nas ações em face dele propostas.

Portanto, vemos que o instituto da Assistência Jurídica Gratuita é o direito a ter um profissional da área jurídica que seja habilitado, para obter uma consultoria, orientação sobre seus direitos e também de ter um representante ao ingressar no judiciário. Este serviço é prestado pela Defensoria Pública, que é um órgão constitucional que presta um serviço de atendimento jurídico as pessoas hipossuficientes.

Cunha (2018, p. 33-34) define a assistência judiciária gratuita como um direito "assegurado ao cidadão para ser representado em juízo por um procurador habilitado e ainda exemplifica que poderá ser por meio de instituições de ensino que tenham esse serviço, advogados particulares que possuem convênios ou ainda nomeados pelo Poder Judiciário"

Sendo assim, é perceptível que a assistência judiciária é o direito de ser representado em juízo, difere da assistência jurídica, pois lá essa representação se dará necessariamente pela Defensoria Pública, e aqui pode haver a representação por diferentes formas.

Cunha (2018, p. 39) conceitua a Justiça Gratuita como "a dispensa total ou parcial, do custeio pela parte das despesas processuais". Assim sendo, a Justiça Gratuita possibilita a dispensa das despesas processuais e extraprocessuais se essas forem necessárias, sendo que a pessoa deverá requerer este benefício no juízo da causa, ou seja, já temos um processo.

Dessa forma, vemos que não há motivos de ter a confusão destes institutos, pois cada um deles possui sua peculiaridade e ainda o Novo Código de Processo Civil possui um tópico somente para regular a Gratuidade da Justiça enquanto a assistência judiciária é regulada pela Lei 1.060/1950 e pela Constituição Federal.

\subsubsection{Importância da justiça gratuita como meio garantidor do acesso à justiça}

$\mathrm{O}$ acesso à justiça possui duas finalidades, sendo a primeira delas o acesso ao judiciário e a outra a efetividade, satisfação desse acesso. Souza (2011) assevera que não basta garantir o acesso à justiça, considerando-o como uma porta de entrada, mas também deve ser uma porta de saída, ou seja, permitir que se tenha uma decisão justa e eficaz.

Além disso, conceitua-se o instituto do benefício da justiça gratuita que nada mais é que a dispensa do pagamento das custas advindas de um processo. Assim sendo, verifica-se que existe um enorme vínculo entre o benefício da justiça gratuita e o acesso à justiça. Sua conexão se dá pelo fato de existir um direito e uma ferramenta para assegurar este direito, ou seja, o benefício da justiça gratuita é uma ferramenta que garante um efetivo direito de acesso à Justiça.

$\mathrm{O}$ instituto do benefício da justiça gratuita permite o acesso à justiça daqueles que não possuem recursos suficientes para arcar com as despesas do processo. Isso não torna o Poder Judiciário gratuito, apenas permite que todos tenham direito de ter acesso a ele.

Bueno (2014) assevera que o intuito do art. 5º LXXIV, da Constituição da República Federativa do Brasil de 1988 não é tornar a prestação jurisdicional gratuita, mas evitar que o pagamento dos custos da atividade jurisdicional, seja um obstáculo para aqueles que não tem condições de efetuar o pagamento.

$\mathrm{O}$ art. $5^{\circ}$, LXXIV, da Constituição da República Federativa do Brasil de 1988 dispõe que àqueles que não possuem condições financeiras não podem deixar de ter acesso ao judiciário, pelo fato da prestação da atividade jurisdicional ter custos. Para tanto, o Estado, assume para si todos os custos de um processo e tira a responsabilidade do pagamento desses custos daquele que não possui condições financeiras (Bueno, 2014).

Dessa forma, não existem dúvidas de que este instituto do benefício da justiça gratuita é um instrumento que permite que seja dado o primeiro passo para aqueles que querem defender ou exercer seus direitos. Além disso, o benefício não serve apenas para o início, ele perdura durante todo o processo, pelo fato de podermos ter o direito efetivado, satisfeito. 
Assim sendo, verifica-se que o instituto do benefício à justiça gratuita reforça o acesso à justiça, pois é por meio dele que aqueles considerados pobres, ou seja, que não detém condições de suportar os custos de um processo iniciem o seu acesso à justiça, desonerando todas as despesas que o processo poderá gerar, garantindo então um acesso à justiça homogêneo.

\subsection{Surgimento da justiça gratuita no Brasil}

\subsubsection{O marco do benefício da justiça gratuita em 1950}

Na data de 05 de fevereiro de 1950, entrou em vigor a Lei 1.060, denominada como Lei da Assistência Judiciária, que regulamentava normas de acesso à justiça para aqueles que fossem hipossuficientes. Nesse sentido, in verbis o parágrafo único do art. $2^{\circ}$ :

Art. $2^{\circ}$. Gozarão dos benefícios desta Lei os nacionais ou estrangeiros residentes no país, que necessitarem recorrer à Justiça penal, civil, militar ou do trabalho.

Parágrafo único. - Considera-se necessitado, para os fins legais, todo aquele cuja situação econômica não lhe permita pagar as custas do processo e os honorários de advogado, sem prejuízo do sustento próprio ou da família.

Pelo fato do Código de Processo Civil de 1973 apenas prever a possibilidade da justiça gratuita, mas não regulamentar este instituto de forma específica, a Lei 1.060/1950 continuou regulamentando o assunto até a vigência do Novo Código de Processo Civil de 2015. Para a concessão do benefício, bastava uma simples afirmação do declarante de que não possui condições de arcar com custas e honorários, sem prejuízo próprio e de sua família, na própria petição inicial ou em seu pedido. Segundo o art. $4^{\circ}$ : “Art. $4^{\circ}$ A parte gozará dos benefícios da assistência judiciária, mediante simples afirmação, na própria petição inicial, de que não está em condições de pagar as custas do processo e os honorários de advogado, sem prejuízo próprio ou de sua família".

Entretanto, o parágrafo $1^{\circ}$, exigia a comprovação de rendimento e atestado de pobreza expedido por autoridade policial ou Prefeito Municipal, sendo dispensado à vista de contrato de trabalho comprobatório de que esse percebe salários igual ou inferior ao dobro do mínimo legal regional para o gozo da gratuidade de justiça. Posteriormente, sobreveio a Lei $\mathrm{n}^{\circ}$ 6.654, de 30 de maio de 1979 que possibilitou "Art. $4^{\circ}$, § $3^{\circ}$ - A apresentação da carteira de trabalho e previdência social, devidamente legalizada, onde o juiz verificará a necessidade da parte, substituirá os atestados exigidos nos $\S \S 1^{\circ}$ e $2^{\circ}$ deste artigo" (Brasil, 1979).

Com a edição da Lei 7.115 de 29 de agosto de 1983, foi abolido o atestado de pobreza e instituída a autodeclararão de hipossuficiência econômica, com imposição de presunção de veracidade ao conteúdo declarado. Por fim, com a edição da Lei $\mathrm{n}^{\circ} 7.510$, de 4 de julho de 1986, a redação do art. $4^{\circ}$ e seus parágrafos foi novamente alterada, passando a vigorar com os seguintes dizeres: "§ $1^{\circ}$. Presume-se pobre, até prova em contrário, quem afirmar essa condição nos termos desta lei, sob pena de pagamento até o décuplo das custas judiciais", que permaneceu em vigor até o Novo Código de Processo Civil (BRASIL, 1986).

Nos termos da Lei, apesar de alterações com o decorrer dos anos, o pedido de gratuidade é acompanhado de declaração de pobreza que possui presunção de veracidade. Segundo Marcacini (1996, p. 100), "presume-se verdadeira a declaração de pobreza, sendo que o impugnante que tem o ônus de provar que não existe a condição de pobreza".

Dessa forma, na petição inicial ou em declaração de próprio punho, era, de regra, suficiente a admissão do benefício, por traduzir presunção. As normas para que pudesse ser concedido o pedido, visavam à condição de carência do requerente como presunção juris tantum, ou seja, relativa, admitindo então prova em contrário, podendo ser cortada a qualquer momento, por meio de impugnação da parte contrária ou pelo próprio juiz de ofício. 
A expressão "assistência judiciária" expressa no art. 5, está relacionado com o direito de ser representado em juízo, oferecido pelo Estado ou por entidades não estatais conveniadas ou não ao Poder Público. Enquanto os arts. $6^{\circ}, 7^{\circ}, 8^{\circ}$ e $9^{\circ}$ da Lei em questão, a expressão assistência judiciária é utilizada no sentido de justiça gratuita.

\subsubsection{O papel da Constituição da República Federativa do Brasil de 1988}

A Constituição da República Federativa do Brasil de 1988 se preocupou com os aspectos sociais da pessoa natural ou jurídica, brasileira ou estrangeira, elencando os direitos sociais como um dos direitos fundamentais. $\mathrm{O}$ acesso à justiça ganhou status de direito fundamental, e concernente à justiça gratuita, possibilitou que as pessoas que não tivessem condições de arcar com o pagamento das despesas processuais pudessem ter acesso livre ao Poder Judiciário.

Mesmo existindo uma legislação que regulasse o tema (Lei 1.060/1950), a gratuidade da justiça ganhou força com o advento da Constituição da República Federativa do Brasil de 1988, pois completou o rol de direitos individuais, que são considerados como direitos fundamentais. O artigo 5. ${ }^{\circ}$ LXXIV, da Constituição Federal dispõe:

Art. 5. ${ }^{\circ}$ Todos são iguais perante a lei, sem distinção de qualquer natureza, garantindo aos brasileiros e aos estrangeiros residentes no País a inviolabilidade do direito à vida, à liberdade, à segurança e à propriedade, nos termos seguintes:

$[\ldots]$

LXXIV - o Estado prestará assistência jurídica integral e gratuita aos que comprovarem insuficiência de recursos.

Ao analisar o dispositivo da Carta Magna, verifica-se que o Estado prestará assistência judiciária gratuita para aqueles que comprovarem a insuficiência de recursos, não basta uma mera afirmação de pobreza para que o benefício seja deferido; é necessário que tenha uma prova mínima de que realmente não possui condições de arcar com as despesas de um processo.

O inciso LXXIV, do art. $5^{\circ}$, não deixou claro de que forma comprovar a insuficiência de recursos. Isso mostra que cada magistrado atuará de forma discricionária, ele mesmo determinando quais provas deverão ser produzidas para que se tenha o deferimento da justiça gratuita, seguindo a Lei vigente.

Vale lembrar que o dispositivo supracitado serve como norte para a interpretação do papel a ser desempenhado pela Defensoria Pública, instituição permanente essencial para à função jurisprudencial (art. 134):

Art. 134. A Defensoria Pública é instituição permanente, essencial à função jurisdicional do Estado, incumbindo-lhe, como expressão e instrumento do regime democrático, fundamentalmente, a orientação jurídica, a promoção dos direitos humanos e a defesa, em todos os graus, judicial e extrajudicial, dos direitos individuais e coletivos, de forma integral e gratuita, aos necessitados, na forma do inciso LXXIV do art. $5^{\circ}$ desta Constituição Federal (Brasil, 1988).

\subsubsection{Fundamentos para a mudança no Novo Código de Processo Civil}

O Novo Código de Processo Civil disciplina a Assistência Judiciária Gratuita na Seção IV do Capítulo II e revogou de forma expressa alguns artigos da Lei $\mathrm{n}^{\circ}$ 1.060/50, nos termos do artigo 1.072, III. Entretanto, continuou regulamentando os mesmos benefícios aos necessitados. Além disso, houve uma inovação no Novo Código de Processo Civil ao permitir à concessão do benefício da justiça gratuita às pessoas jurídicas, pois até o momento somente pessoas físicas poderiam requerer o benefício.

No tocante ao requerimento e concessão do benefício da justiça gratuita, continuou a mesma disposição e entendimento formado desde o início da vigência da Lei 1.060/1950, dispondo que o pedido feito por pessoa física ou natural, possui presunção de veracidade juris tantum, ou seja, relativa. 
Montenegro Filho (2017, p. 147), ainda diz que não se exige juntada de documentos, como extratos bancários, instrumentos de protesto, comprovante de seguro-desemprego. Salvo se o juiz observar por meio do que consta nos autos, elementos que demonstrem a falta de pressupostos legais para que seja concedido o benefício da justiça gratuita.

\subsection{Concessão do benefício da justiça gratuita pelos tribunais a luz do novo CPC}

\subsubsection{Benefício da justiça gratuita no Novo Código de Processo Civil}

A Lei Ordinária Federal 13.105/2015, instituiu o Novo Código de Processo Civil brasileiro, insere um capítulo para regulamentar integralmente sobre a gratuidade da justiça, contendo cinco artigos, seja do artigo 98 ao 102 . O caput do art. 98 do Novo Código de Processo Civil, dispõe que terá direito ao benefício da justiça gratuita a pessoa natural ou jurídica, brasileira ou estrangeira que possuir insuficiência de recursos para arcar com o pagamento das custas, despesas processuais e os honorários advocatícios.

A pessoa beneficiada pela justiça gratuita será dispensada segundo o $§ 1^{\circ}$ do art. 98 do Novo Código de Processo Civil das seguintes situações:

I - as taxas ou as custas judiciais;

II - os selos postais;

III - as despesas com publicação na imprensa oficial, dispensando-se a publicação em outros meios;

IV - a indenização devida à testemunha que, quando empregada, receberá do empregador salário integral, como se em serviço estivesse;

$\mathrm{V}$ - as despesas com a realização de exame de código genético - DNA e de outros exames considerados essenciais;

VI - os honorários do advogado e do perito e a remuneração do intérprete ou do tradutor nomeado para apresentação de versão em português de documento redigido em língua estrangeira;

VII - o custo com a elaboração de memória de cálculo, quando exigida para instauração da execução;

VIII - os depósitos previstos em lei para interposição de recurso, para propositura de ação e para a prática de outros atos processuais inerentes ao exercício da ampla defesa e do contraditório;

IX - os emolumentos devidos a notários ou registradores em decorrência da prática de registro, averbação ou qualquer outro ato notarial necessário à efetivação de decisão judicial ou à continuidade de processo judicial no qual o benefício tenha sido concedido (BRASIL, 2015).

É importante ressaltar que o estrangeiro, sendo pessoa natural, goza das mesmas garantias do $\S 3^{\circ}$ do art. 99 do Novo Código de Processo Civil. Já as pessoas jurídicas (sem restrição de possuir ou não finalidade lucrativa) deverão comprovar nos autos em que pleiteia o benefício da justiça gratuita, o pressuposto exigido no art. 98 do Novo Código de Processo Civil, que é "a insuficiência de recursos", sob pena de ter seu pedido indeferido.

Dessa forma, o requisito essencial para que haja o deferimento do benefício da justiça gratuita é a "insuficiência de recursos". Porém, este é um conceito indeterminado, um requisito genérico, não existindo em nossa legislação uma definição do que seria a insuficiência de recursos. Segundo Theodoro Júnior (2018, p. 336): "Necessitado, para o legislador, não é apenas o miserável, mas, sim, aquele com insuficiência de recursos para pagar às custas, despesas processuais e honorários advocatícios".

Portanto, o requerente do benefício não precisa ser miserável, ou ainda, viver em situação de pobreza, pois será verificada sua condição financeira frente aos valores que precisarão ser pagos no processo, ou seja, basta não possuir recursos financeiros suficientes para arcar com às custas, despesas processuais e honorários advocatícios. Sendo assim, mesmo que o cidadão tenha bens poderá ser beneficiado com a justiça gratuita, se não possuir renda para custear as referidas despesas.

Para Montenegro Filho (2017, p. 146): “o estado de pobreza não é verificado somente através do patrimônio da requerente, mas da sua situação financeira, analisando suas receitas e despesas, em cotejo com o valor das custas processuais”. A renda do requerente não poderá ser ignorada, mas é inadequado que se faça uma fixação de renda máxima para deferir ou indeferir o benefício (Cunha, 2018). 
Entretanto, "a concessão de gratuidade não afasta a responsabilidade do beneficiário pelas despesas processuais e pelos honorários advocatícios decorrentes de sua sucumbência" (art. 98, § $2^{\circ}$ ) e "[...] vencido o beneficiário, as obrigações decorrentes de sua sucumbência ficarão sob condição suspensiva de exigibilidade e somente poderão ser executadas se, nos 5 anos, anos subsequentes ao trânsito em julgado da decisão" (art. 98, § 3º (Brasil, 2015).

Além disso, é importante ressaltar que a gratuidade "não afasta o dever de o beneficiário pagar, ao final, as multas processuais que lhe sejam impostas" (art. $98, \S 4^{\circ}$ ) e o benefício poderá ser concedido "em relação a algum ou a todos os atos processuais” (art. 98, § 5), todavia a Lei não determina como essas condições se aplicam (Brasil, 2015).

Segundo do caput do art. 99, para a concessão do benefício da justiça gratuita, é indispensável que haja pedido expresso da parte autora na petição inicial e a da parte ré, na contestação, sendo vedado que o juiz conceda de ofício. Entretanto, é importante ressaltar que a justiça gratuita pode ser pedida a qualquer momento, ou seja, na petição, na contestação, na petição para ingresso de terceiro no processo ou em recurso, como está expresso no Novo Código de Processo Civil, no $§ 1^{\circ}$ do art. 99 , in verbis:

Art. 99. O pedido de gratuidade da justiça pode ser formulado na petição inicial, na contestação, na petição para ingresso de terceiro no processo ou em recurso.

$\S 1^{\circ}$ Se superveniente à primeira manifestação da parte na instância, o pedido poderá ser formulado por petição simples, nos autos do próprio processo, e não suspenderá seu curso (Brasil, 2015).

O art. $99, \S 2^{\circ}$, dispõe que o juiz somente poderá indeferir o pedido se houver nos autos elementos que evidenciem a falta dos pressupostos legais para a concessão de gratuidade, devendo, antes de indeferir o pedido, determinar à parte a comprovação do preenchimento dos referidos pressupostos. Entretanto, o $\S 3^{\circ}$, do art. 99, presume verdadeira a alegação de insuficiência deduzida exclusivamente por pessoa natural.

Dessa forma, fica evidente que a declaração não possui presunção absoluta e sim relativa, uma presunção juris tantum, que admite prova em contrário, podendo assim o juiz dentro de seus poderes, conferir e analisar a veracidade da declaração juntada aos autos.

Sobre isso Moreira (1977, p. 60) conceitua a presunção juris tantum como uma presunção onde se tem possibilidade de verificar se possui ou não força suficiente de persuadir.

Cunha (2018, p. 58) assevera que não se pode ignorar a atividade profissional da parte, a natureza da demanda se envolver vultuosas somas ou ainda se for de financiamento de bens de luxo com altas parcelas, de forma que a insuficiência de recursas seja incompatível.

Sendo assim, nesses casos não se terá o indeferimento imediato do benefício da justiça gratuita, mas será necessário que a parte comprove sua situação econômica ao juízo, por meio de documentos, de acordo com o caso concreto.

Dessa forma, considera-se que o Novo Código de Processo Civil, está claro que para a concessão do benefício da justiça gratuita a mera declaração de insuficiência de recursos é suficiente, havendo dúvidas quanto essa declaração é que se oferece a parte a oportunidade de levar aos autos documentos que comprovem sua hipossuficiência.

\subsubsection{Análise jurisprudencial}

Segundo a redação do Novo Código de Processo Civil, para ser concedido a gratuidade da justiça é muito fácil, basta alegar que não possui condições de arcar com às custas do processo, sem que prejudique seu próprio sustento ou de sua família.

Diante dessa facilidade, tem sido comum muitas pessoas abusarem desse benefício, ou seja, pessoas desonestas tem se utilizado dessa ferramenta para ajuizar ações desnecessárias, pois serão isentos do custo que uma demanda possui. 
Dessa forma, embora o Novo Código de Processo Civil, exija apenas a mera declaração de hipossuficiência para comprovar a insuficiência de recursos, isso tem sido algo muito subjetivo, uma vez que não existe uma previsão legal que defina os critérios que deverão ser analisados.

Diante disso, alguns magistrados têm definido seus próprios critérios para analisar o pedido da gratuidade da justiça, pedindo então que a parte requerente junte nos autos documentos que sejam capazes de comprovar sua insuficiência econômica.

No processo $\mathrm{n}^{\circ}$ 20190764920188260000, o Tribunal de Justiça do estado de São Paulo exige que o requerente do benefício da Justiça Gratuita, comprove que não possui capacidade financeira para realizar o pagamento das custas e despesas processuais por meio de cópia das últimas folhas da carteira do trabalho, comprovante de sua renda mensal e de seu eventual cônjuge, cópia dos extratos bancários de contas de sua titularidade e do eventual cônjuge dos últimos três meses, cópia dos extratos de cartão de crédito dos últimos três meses e cópia da última declaração do imposto de renda não bastando à mera declaração de hipossuficiência, pois ela não possui presunção absoluta (São Paulo, 2018).

Para o Tribunal de Justiça do estado de Santa Catarina, a concessão do benefício da justiça gratuita, tem-se exigido não só a simples declaração de hipossuficiência da parte, mas a juntada de outros documentos que demonstrem a real necessidade da benesse. No caso $\mathrm{n}^{\circ}$ 0032226-59.2016.8.24.0000, o juiz determinou que o autor comprovasse o rendimento atualizado, apresentando carteira de trabalho ou outros documentos que informe sua incapacidade financeira, seguindo o preceito ex positis (Santa Catarina, 2016).

O Tribunal de Justiça do estado do Paraná, destaca que somente fará jus do benefício de justiça gratuita aqueles que não possuem patrimônio nem rendimentos suficientes para arcar com as custas processuais e honorários sem prejuízo da sua subsistência. No processo cível e do trabalho $\mathrm{n}^{\circ}$ 00590203720198160000, o magistrado determinou a juntada de provas aos autos que demonstrassem a incapacidade financeira do agravante, como titularidade de veículos, imóveis e propriedades que lhe garante renda, para análise da justiça gratuita anteriormente deferida (Paraná, 2020).

Apesar de a simples afirmação de pobreza gozar de presunção juris tantum, certo é que os magistrados podem indeferir o benefício, caso constate a inexistência de provas que ampararam a alegação de hipossuficiência financeira, conforme se verifica, in casu (Santa Catarina, 2016; São Paulo, 2018; Paraná, 2020).

Da mesma forma tem entendido o magistrado do processo $\mathrm{n}^{\circ} 10000190335240001$ do Tribunal de Justiça do estado de Minas Gerais, que destaca que para a concessão do benefício, é necessário que a insuficiência alegada na declaração seja comprovada através de cópia da carteira de trabalho e previdência social e folhas de pagamento, não sendo possível uma concessão do benefício automática, com a simples declaração (Minas Gerais, 2019a).

No entendimento de alguns magistrados, em atendimento ao disposto no art. $5^{\circ}$, LXXIV da Constituição Federativa do Brasil 1988, as benesses da assistência jurídica integral e gratuita são concedidas aos que comprovarem insuficiência de recursos. Para análise dos documentos comprobatórios da alegada hipossuficiência, utiliza-se a análise fática da situação financeira da parte. Comprovada a hipossuficiência por meio de documentos hábeis, impõe-se o deferimento da gratuidade da justiça (Minas Gerais, 2019a).

Entretanto, ainda existe uma controversa pela presunção de veracidade juris tantum, onde em alguns tribunais ainda deferem a gratuidade de justiça pela mera declaração de hipossuficiência do interessado.

No processo $\mathrm{n}^{\circ} 06219187620178060000$ do Tribunal de Justiça do estado do Ceará, a benefício foi concedido baseado presunção de veracidade juris tantum. No entendimento do magistrado a presunção de veracidade é primado nos princípios constitucionais, em especial o do acesso à justiça, basta a mera declaração de hipossuficiência do interessado para que o mesmo receba os benefícios da justiça gratuita (Ceará, 2018). 
No entendimento do magistrado no processo $\mathrm{n}^{\circ} 10000181299769001$ do Tribunal de Justiça do estado de Minas Gerais, para a concessão do benefício da justiça gratuita, basta a simples afirmação da parte de que não possui condições de arcar com as despesas do processo, sem prejuízo próprio ou de sua família, cabendo à parte contrária, por se tratar de presunção relativa, comprovar a inexistência ou a cessação do alegado estado de pobreza, ou ao Juiz averiguar a veracidade do alegado através de apuração iniciada de ofício, como prevê o Novo Código de Processo Civil em vigor, em seu art. 99, $\S 2^{\circ}$ (Minas Gerais, 2019b).

Dessa forma, presunção de veracidade da alegação de insuficiência de recursos "deduzida exclusivamente por pessoa natural" ( $\$ 3^{\circ}$, art. 99, Novo Código de Processo Civil), que somente poderá ser desconstituída "de ofício" pelo Magistrado, "quando houver nos autos elementos que evidenciem a falta dos pressupostos legais para a concessão da gratuidade" $\left(\S 2^{\circ}\right.$ art. 99, Novo Código de Processo Civil). Determinada a comprovação da alegada hipossuficiência e desonerando-se a parte requerente de tal múnus, impõe-se o deferimento do pedido" (Minas Gerais, 2019b).

A jurisprudência do Tribunal Regional do Trabalho da $3^{\mathrm{a}}$ região, $8^{\mathrm{a}}$ turma, orienta que pode o juízo, embora haja declaração da parte de sua hipossuficiência jurídica para fins de concessão dos benefícios da gratuidade de justiça, investigar sobre a real situação financeira do requerente, haja vista a presunção relativa de veracidade que ostenta a declaração (Minas Gerais, 2019c).

Sendo assim, verifica-se que não existe uma unificação quanto à necessidade de comprovar a hipossuficiência, pois mesmo que a maioria da jurisprudência exija que junte aos autos provas de sua real situação financeira, não há um padrão de documentos a serem juntados, ao passo, que ainda existe uma minoria que defere o benefício utilizando-se da mera declaração de hipossuficiência.

\subsection{A importância do direito do benefício da justiça gratuita garantido e a responsabilidade por sua pretensão}

\subsubsection{Revisão do posicionamento da jurisprudência quanto ao deferimento do benefício da justiça gratuita}

O benefício de justiça gratuita é um direito garantindo a todas as pessoas com insuficiência de recursos para pagar as custas, encargos processuais e os honorários advocatícios. Compete ao magistrado deferir o benefício de forma integral ou parcial, caso os autos apresentem elementos suficientes que evidenciam os pressupostos legais para a concessão de gratuidade de justiça.

O caput do art. 98 do Novo Código de Processo Civil, dispõe que terá direito ao benefício da justiça gratuita a pessoa natural ou jurídica, brasileira ou estrangeira desde comprovar insuficiência de recursos. O Tribunal de Justiça do estado do Mato Grosso no processo ${ }^{\circ} 10050455820188110000$, destaca que o art. 98 do Novo Código de Processo Civil merece uma interpretação extensiva e consensual conjuntamente com o artigo $5^{\circ}$, inciso LXXIV, da Constituição Federal, pois, mesmo que a Lei infraconstitucional preveja a concessão dos benefícios da assistência judiciária, mediante simples afirmação de hipossuficiência econômica, a Constituição Federal de 1988, expressamente, condiciona o seu deferimento à comprovação da necessidade em obtê-los. Cabe ao julgador examinar a razoabilidade da concessão da gratuidade da justiça, considerando para tanto os elementos que evidenciam a condição de necessidade do beneficiário (Mato Grosso, 2019).

Já no caso da pessoa jurídica, a afirmação de hipossuficiência econômica não é suficiente para a concessão do benefício, sendo necessário a comprovação da ausência de recursos. O Tribunal Regional do Trabalho da $20^{\mathrm{a}}$ região, in casu, deferiu o benefício a recorrente, uma vez que, apresentou prova hábil acerca de ausência de condições econômicas para arcar com as despesas processuais, em especial tendo em vista que em razão da pandemia do COVID-19 e por sua atividade não ser caracterizada por serviço essencial, estando, portanto, paralisada (Sergipe, 2020).

Por outro lado, a concessão do benefício da gratuidade da justiça não afasta a responsabilidade do beneficiário pelas despesas processuais e pelos honorários advocatícios da parte contrária, decorrentes a sua sucumbência. O Tribunal Regional 
do Trabalho da $1^{\text {a }}$ região destaca que o ganhador da demanda só poderá executar as despesas e honorários se provar se houve mudança do beneficiário em até 5 (cinco) anos, contado do trânsito julgado, passado o prazo, tais obrigações se extinguem (Rio de Janeiro, 2019b).

$\mathrm{Na}$ decisão recorrida no processo $\mathrm{n}^{\mathrm{0}}$ 00115502020188130520, o magistrado modificou a sentença para que haja distribuição dos ônus de sucumbência, em razão da reciprocidade sucumbencial, em que a apelante foi condenada ao pagamento de $70 \%$ das custas e dos honorários sucumbenciais, fixados estes em $10 \%$ sobre o valor da condenação, eis que litiga sob o pálio da justiça gratuita (Minas Gerais, 2018).

Além disso, o art. 99 do Novo Código de Processo Civil destaca que o benefício de justiça gratuita pode ser pleiteado na petição, na contestação, na petição para ingresso de terceiro no processo ou em recurso. No entendimento do Tribunal Regional do Trabalho da $1^{a}$ região, o mesmo o benefício de justiça gratuita pode ser requerido a qualquer tempo, desde que presente condições de miserabilidade, informando a parte que não está em condições de pagar as despesas processuais sem prejuízo do próprio sustento ou de sua família. No caso concreto, a recorrente insatisfeita com a sentença Id. 632bc78, entrou com recurso renovando os pedidos de justiça gratuita e honorários de sucumbência (Rio de Janeiro, 2019a).

$\mathrm{O}$ art. $99, \S 2^{\circ}$ e $3^{\circ}$ do Novo Código de Processo Civil contemplam que o benefício será indeferido apenas quando houver elementos que evidenciem a existência de recursos suficientes para o pagamento das custas, além de estabelecer uma presunção de veracidade das declarações de hipossuficiência. No processo $\mathrm{n}^{\circ} 15888538$ do Tribunal de Justiça do estado do Paraná, o magistrado intimou-se a parte agravante para sobre eles se manifestar, bem assim para que apresentasse, no prazo de 05 (cinco) dias, a declaração do Imposto de Renda relativa ao último exercício fiscal, incluindo relação de bens, entretanto o agravante não comprovou fazer jus ao benefício de justiça gratuita, tendo seu pedido indeferido (Paraná, 2017).

Com presunção veracidade ou prova, cabe a defensoria pública ou órgão equivalente prestar assessoria jurídica, aceitando a possibilidade da contratação de um advogado particular. O art. 99, $\S 4^{\circ}$, do Novo Código de Processo Civil, aceita a possibilidade de deferimento do pedido de gratuidade de justiça, mesmo com a contração de um advogado particular. Segundo o Tribunal de Justiça de Minas Gerais no processo $n^{\circ}$ 10433130141255001, a assistência do requerente por advogado particular não impede a concessão de gratuidade da justiça e não havendo contraprova, deve prevalecer o direito ao benefício (Minas Gerais, 2020).

\subsubsection{A Responsabilidade pelo pedido do benefício da justiça gratuita}

A formulação do pedido para obter o benefício da justiça gratuita, é simples, ou seja, basta uma mera afirmação da parte dizendo não possuir condições financeiras suficientes para arcar com às custas do processo. Devido essa simplicidade, muitas pessoas afirmam não possuir capacidade financeira para suportar estes gastos, porém sua realidade econômica é diferente do que foi afirmado.

O Novo Código de Processo Civil possui um regime de sanção para aqueles que pedirem o benefício da justiça gratuita indevidamente, o parágrafo único do art. 100 dispõe:

Art. 1000 Revogado o benefício, a parte arcará com as despesas processuais que tiver deixado de adiantar e pagará, em caso de má-fé, até o décuplo de seu valor a título de multa, que será revertida em benefício da Fazenda Pública estadual ou federal e poderá ser inscrita em dívida ativa.

Didier Junior e Oliveira (2016) asseveram que se houver a má-fé do ex-beneficiário, seja daquele que requereu o benefício indevidamente, seja daquele que deixou de ser hipossuficiente, mas não informou o fato ao juízo, deverá pagar multa de até dez vezes do valor que deixou de adiantar até então ou de tudo que deixou de adiantar após o incremento. 
A má-fé não se dará pelo simples fato de o juiz ter indeferido o pedido da parte, mas sim quando ela faz o pedido sobre o ângulo da má-fé, que neste caso deverá pagar a multa que chegará até o décuplo de seu valor.

O legislador sempre presumirá a boa-fé, porém caso houver pedidos em que o requerente teve uma conduta desonesta, omitindo seus patrimônios e receitas ou que pelo fato do pedido ser simples a pessoa se aproveitar da situação será imputado a essas responsabilidades.

A multa de até o décuplo de seu valor é uma sanção específica de natureza administrativa, que será imposta para aquele que agiu de má-fé, em benefício da Fazenda Pública, pois de imediato seria ela que suportaria todos os prejuízos do pedido que foi concedido de forma indevida.

Cunha (2018, p. 104) compreende ser cabível cumular juntamente com o art. 100 do Código de Processo Civil, a indenização prevista no art. 81 do mesmo Código, quando houver a violação de ambas as normas, sendo que, a última tem o caráter de indenizar.

\section{Conclusão}

Com o surgimento do Novo Código de Processo Civil houve a regulamentação do benefício da justiça gratuita de uma forma mais detalhada, porém continuou prevendo que a declaração de hipossuficiência é o suficiente para o deferimento do benefício da justiça gratuita. Porém, ao analisar a posição da jurisprudência, demonstrou-se que há inúmeras divergências nas decisões dos tribunais, principalmente quanto ao posicionamento do Deferimento do Benefício da Justiça Gratuita nos termos da Lei Ordinária Federal 13.105/2015, principalmente pelo fato da declaração possuir uma presunção relativa, fato que faz os magistrados adotarem seus próprios critérios, sejam eles subjetivos ou discricionários para conceder o benefício. Entretanto, ao analisarem o pedido de acordo com seus próprios critérios, é perceptível que existe uma aplicação desigual da lei, sendo necessário a criação da uniformização quanto a comprovação dessa insuficiência, para que a lei seja aplicada de uma forma igual para todos.

Por conseguinte, por se tratar de um importante instituto do ordenamento jurídico o legislador preocupou-se em garantir que o benefício não seja utilizado de forma displicente e sem critérios, visto que o Código de Processo Civil prevê que caso seja comprovada a insuficiência de recursos, o benefício deve ser deferido. Porém, caso a parte seja beneficiada, não importando a natureza jurídica da mesma, seja pessoa natural ou jurídica, nacional ou estrangeira, e seja comprovada a má-fé, deve o benefício ser revogado, e ainda, deve a parte arcar com as despesas processuais que tiver deixado de adiantar, podendo ainda pagar até o décuplo de seu valor a título de multa.

\section{Referências}

Alexy, R. (2008). Teoria dos direitos fundamentais. Tradução de Virgílio Afonso da Silva. Malheiros.

Aristóteles. (1996) Livro V da Ética a Nicômaco. Nova Cultura.

Bastos, C. L \& Keller, V. (1995). Aprendendo a aprender. Vozes.

Brasil (2019). Constituição. Constituição da República Federativa do Brasil de 1988. In: Vade Mecum. Saraiva.

Brasil. (1950). Lei n ${ }^{\circ} 1.060$, de 5 de fevereiro de 1950. Estabelece normas para a concessão de assistência judiciária aos necessitados. Diário Oficial da União, Brasília. http://www.planalto.gov.br/ccivil_03/leis/11060compilada.htm.

Brasil. (2015) Lei $\mathrm{n}^{\circ}$ 13.105, de 16 de março de 2015. Código de Processo Civil. Diário Oficial da União, Brasília. http://www.planalto.gov.br/ccivil_03/_ato2015-2018/2015/lei/113105.htm.

Bueno, C. S. (2014). Curso Sistematizado de direito processual civil: teoria geral do direito processual civil. (8a ed.), Saraiva, v.8.

CappellettI, M. \& Garth, B. (1998). Acesso à Justiça. Palloti. 
Research, Society and Development, v. 10, n. 13, e224101321183, 2021

(CC BY 4.0) | ISSN 2525-3409 | DOI: http://dx.doi.org/10.33448/rsd-v10i13.21183

Minas Gerais. (2018). Apelação Cível n $\mathrm{n}^{0}$ 00115502020188130520. Relator: Evangelina Castilho Duarte. DJe: 19/012/2018. JusBrasil. https://tjmg.jusbrasil.com.br/jurisprudencia/939907045/apelacao-civel-ac-10520180011550001-pompeu?ref=juris-tabs.

Minas Gerais. (2020). Apelação Cível: 10433130141255001 MG. Relator: José Flávio de Almeida. DJe: 27/05/2020. JusBrasil. https:/tjmg.jusbrasil.com.br/jurisprudencia/931129988/apelacao-civel-ac-10433130141255001-mg?ref=serp.

Montenegro Filho, M. (2017). Novo Código de Processo Civil Comentado. (3a ed.), Atlas.

Moreira, J. C. B. (1977). Temas de Direito Processual. (2a ed.), Saraiva.

Nery Júnior, N. (1997). Princípios do Processo Civil na Constituição Federal. (4a ed.), RT.

Paraná. (2020). Agravo de Instrumento n 0059020-37.2019.8.16.0000, $17^{\text {a }}$ Câmara Cível. Relator: Fabian Schweitzer. DJe: 07/04/2020. JusBrasil. https://tjpr.jusbrasil.com.br/jurisprudencia/832619355/processo-civel-e-do-trabalho-recursos-agravos-agravo-de-instrumento-ai-590203720198160000-pr-00590203720198160000-decisao-monocratica?ref=serp.

Paraná. (2017). Agravo de Instrumento $\mathrm{n}^{\circ}$ 15888538. Relator: Juiz Carlos Henrique Licheski Klein. DJe: 22/08/2017. JusBrasil. https://tjpr.jusbrasil.com.br/jurisprudencia/837248601/agravo-de-instrumento-ai-15888538-pr-1588853-8-acordao/inteiro-teor-837248611?ref=juris-tabs .

Rawls, J. (2000). Uma Teoria da Justiça. (2a ed.), Martins Fontes.

Rio de Janeiro. (2019). Recurso Ordinário trabalhista n ${ }^{\circ} 00000183220195200015$. Relator: Rildo Albuquerque Mousinho de Brito, DJe: 25/09/2019. JusBrasil. https://trt-1.jusbrasil.com.br/jurisprudencia/783536170/recurso-ordinario-trabalhista-ro-1004308520175010009-rj?ref=serp.

Rio de Janeiro. (2019). Recurso Ordinário no 01010939420185010010. Relator: Marcelo Augusto Souto de Oliveira. DJe: 6/10/2019. JusBrasil. https://trt1.jusbrasil.com.br/jurisprudencia/797133546/recurso-ordinario-rito-sumarissimo-ro-1010939420185010010-rj/inteiro-teor-797133556?ref=juris-tabs.

Santa Catarina. (2016). Agravo de Instrumento $\mathrm{n}{ }^{\circ}$ 0032226-59.2016.8.24.0000, $2{ }^{\text {a }}$ Câmara de Direito Comercial. Relator. Des. Robson Luz Va. DJe 13/9/2016. JusBrasil. https://tj-sc.jusbrasil.com.br/jurisprudencia/648410799/agravo-de-instrumento-ai-40177576620188240000-blumenau-4017757$6620188240000 ?$ ref $=$ serp.

São Paulo. (2018). Agravo de instrumento n ${ }^{2}$ 20190764920188260000, $35^{\text {a }}$ Câmara de Direito Privado. Relator: Morais Pucci. DJe 13/03/2018. JusBrasil. https://tj-sp.jusbrasil.com.br/jurisprudencia/557819294/20190764920188260000-sp-2019076-4920188260000?ref=serp.

Sergipe. (2020). Agravo de Instrumento n ${ }^{\circ}$ 00000183220195200015. Relator: Rita de Cassia Pinheiro de Oliveira. DJe: 17/07/2020. JusBrasil. https://trt20.jusbrasil.com.br/jurisprudencia/877460551/183220195200015?ref=serp.

Souza, W. A. (2011). Acesso à justiça. Dois de Julho.

Theodoro júnior, H. (2019). Curso de Direito Processual Civil: teoria geral do direito processual civil processo de conhecimento e procedimento comum. (60a ed.), Forense. 